\title{
"Alongside-the-stiff-guidewire" - a novel variant technique for difficult sigmoid intubation using gastroscope-directed guidewire pre-insertion
}

Colonoscopy completion may occasionally prove tricky, and many tricks of the trade have been reported to this end, albeit mostly on an individual basis [1] Among the myriad rescue techniques when encountering difficult sigmoid intubation is gastroscope-directed guidewire insertion followed by over-the-wire scope insertion after wire backloading onto a colonoscope [2]. Here, a variant technique designated "alongside-thestiff-guidewire" was pioneered and successfully applied without complications in five consecutive patients over the last 12 months (two patients referred and three in-patients, each with sigmoid intubation failures using the conventional colonoscopy approach) ( $\triangleright$ Table 1 ).

The technique implies switching to a standard-size gastroscope to intubate the sigmoid with its sharp angulations, which, given the increased tip flexibility and shorter bending section length, proved easily successful in all individuals. Note the mucosal injury where colonoscope advancement failed ( $\mathbf{F i g} \mathbf{1} \mathbf{a}$ ). In the next step, a stiff Savary-type guidewire with a flexible tip routinely used for esophageal bougienage was inserted carefully to the higher sigmoid (up to about $40 \mathrm{~cm}$ ) and the gastroscope withdrawn ( $\triangleright$ Fig.1 b). Instead of backloading the guidewire onto the colonoscope, e.g., using an endoscopic retrograde cholangiopancreatography (ERCP) catheter, the previously used colonoscope was re-inserted "alongside" the stiff guidewire, speeding up the procedure and reducing related accessory consumption. Owing to the straightening of the anatomy with the guidewire in place, sharp angulations were easily navigated ( $\triangleright$ Fig. $1 \mathbf{c}$ ), and the guidewire was withdrawn after advancement up to its tip to exclude procedure-related mucosal and/or transmural injury, which, indeed, was avoided in all patients. All procedures were completed safely ( $>$ Fig. 1 d, $>$ Video 1 ).

- Table 1 Basic patient characteristics of the five consecutive patients with the "alongside-thestiff-guidewire" technique.

\begin{tabular}{|l|l|l|l|l|}
\hline & Gender & Age & Colonoscopy indication & External referral \\
\hline 1 & Female & 77 & Post-polypectomy surveillance & No \\
\hline 2 & Female & 87 & Exclusion of obstruction & Yes \\
\hline 3 & Female & 69 & Cancer screening & Yes \\
\hline 4 & Female & 62 & Diarrhea & No \\
\hline 5 & Female & 82 & Abdominal pain & No \\
\hline
\end{tabular}
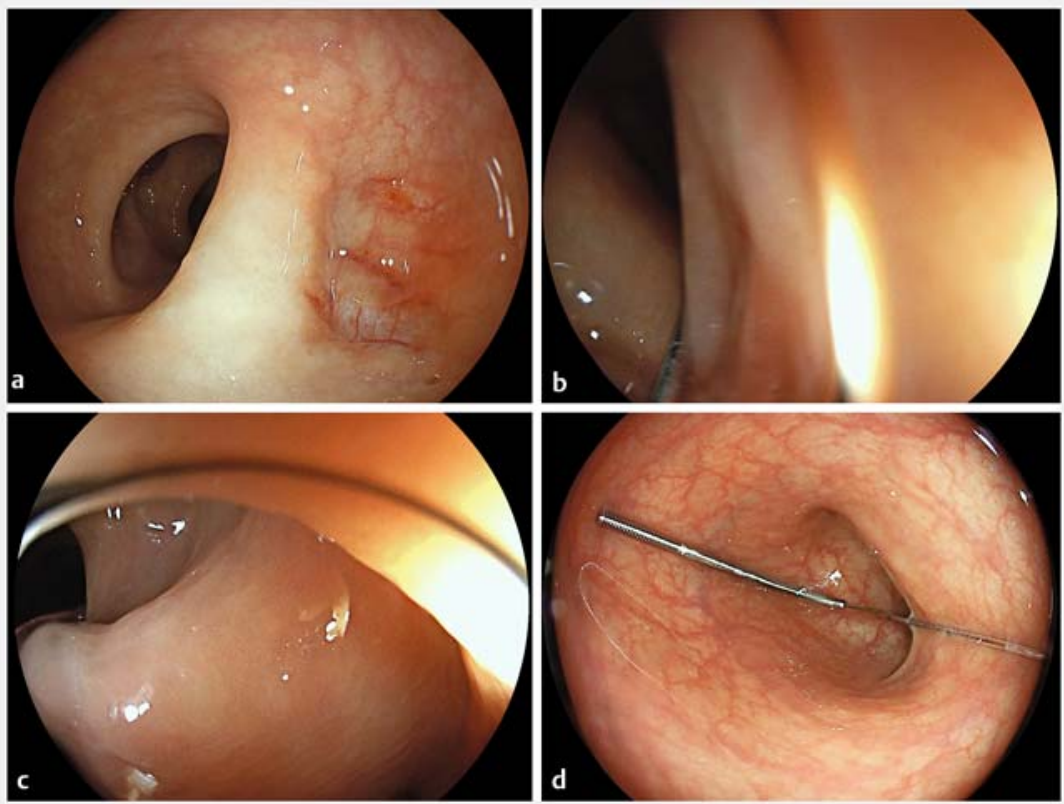

- Fig. 1 Endoscopic still illustration of the "alongside-the-stiff-guidewire" approach in patient 1. a Uncomplicated sigmoid intubation using a standard gastroscope. Note mucosal injury at the rectosigmoid junction (right) due to prior attempts at colonoscope advancement. b Insertion of a stiff guidewire through the gastroscope. c "Alongside-the-stiff-guidewire" sigmoid intubation using the colonoscope. $\mathbf{d}$ Illustration of the flexible tip of the guidewire reached with the colonoscope.

Relative to previously reported rescue techniques, this variant "alongside-thestiff-guidewire" approach represents an attractive simplification owing to the potential benefits of reduced time and accessory consumption and its reliance on ubiquitously available scope technology even in office-based endoscopy services.
Endoscopy_UCTN_Code_CCL_1AD_2A J

Competing interests

The authors declare that they have no conflict of interest. 


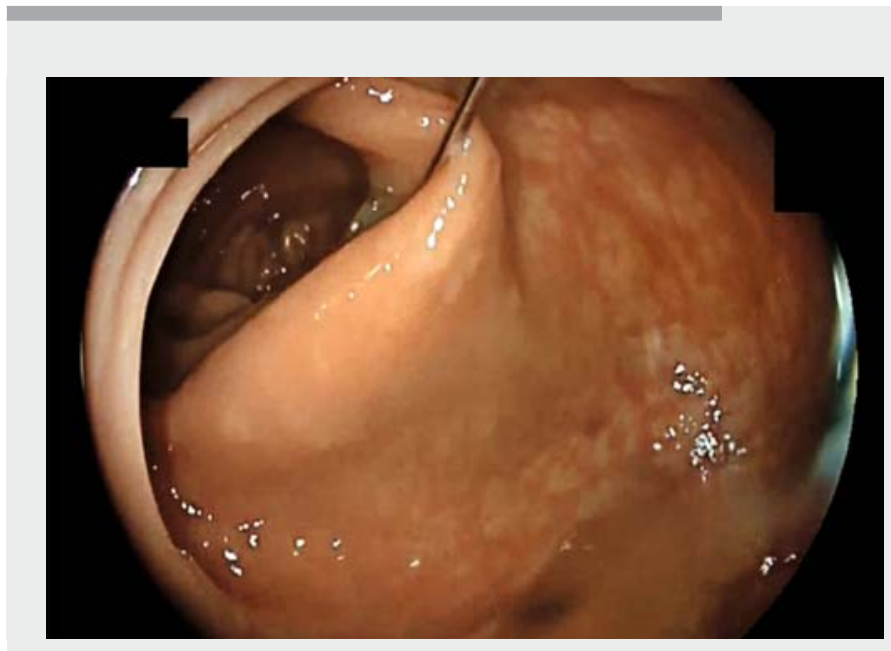

$\checkmark$ Video 1 Dynamic illustration of the "alongside-the-stiff-guidewire" technique in patient 5 .

\section{ENDOSCOPY E-VIDEOS}

https://eref.thieme.de/e-videos

回的回 Endoscopy E-Videos is a free access online section, reporting 回舴: on interesting cases and new techniques in gastroenterological endoscopy. All papers include a high quality video and all contributions are freely accessible online.

This section has its own submission website at https://mc.manuscriptcentral.com/e-videos
The author

\section{Vincent Zimmer ${ }^{1,2}$}

1 Department of Medicine, Marienhausklinik St. Josef Kohlhof, Neunkirchen, Germany

2 Department of Medicine II, Saarland University Medical Center, Saarland University, Homburg, Germany

\section{Corresponding author}

\section{Dr. Vincent Zimmer}

Department of Medicine, Marienhausklinik St. Josef Kohlhof, Klinikweg 1-5, 66539 Neunkirchen, Germany Fax: +49-6821-3632624 vincent.zimmer@gmx.de

\section{References}

[1] Committee AT, Trindade A], Lichtenstein DR et al. Devices and methods to improve colonoscopy completion (with videos). Gastrointest Endosc 2018; 87: 625-634

[2] Ness RM, Gottlieb K, Rex DK et al. Difficult sigmoid colon intubation: guide wire exchange technique. Gastrointest Endosc 1996; 44: 99-101

\section{Bibliography}

Endoscopy 2022; 54: E32-E33

DOI 10.1055/a-1353-4358

ISSN 0013-726X

published online 19.2.2021

(c) 2021. Thieme. All rights reserved.

Georg Thieme Verlag KG, Rüdigerstraße 14,

70469 Stuttgart, Germany 